\title{
A Educação Física na BNCC: desafios da escola republicana
}

\section{RESUMO}

Este estudo consiste em um ensaio teórico que apresenta reflexões acerca das possibilidades e dos desafios impostos pela Base Nacional Comum Curricular. Para tanto, propõe uma discussão sobre república e democracia, localizando a escola como uma instituição formativa necessária para o funcionamento da sociedade. Procura, por fim, analisar o processo de elaboração da base destacando que, embora a efetivação de um currículo comum seja importante para a legitimação da Educação Física como um componente curricular necessário para a escola republicana, o processo final da construção do documento ocorreu de modo pouco democrático, pondo em xeque sua legitimidade.

PALAVRAS-CHAVE: Educação física; Escola republicana; BNCC
George Ivan da Silva Holanda

Licenciado em Educação Física

Universidade Estadual de Goiás, UEG

Goiânia, Goiás, Brasil

geo.holanda07@gmail.com

은ttps://orcid.org/0000-0002-4671-7555

Jane Vanusa Lasch

Especialista em Direito previdenciário

Universidade Anhanguera, UNIDERP, Jataí, Goiás, Brasil

ane.lash1@gmail.com

○ https://orcid.org/0000-0003-1409-3132

\section{Rodrigo Francisco Dias}

Doutor em História

Instituto Federal de Educação, Ciência e

Tecnologia de Minas Gerais Bambuí, Minas Gerais, Brasil

dias.rodrigof@gmail.com

- $\mathrm{https://orcid.org/0000-0003-4791-6625}$ 


\title{
Physical Education at BNCC: challenges of the republican school
}

\begin{abstract}
The present study consists of a theoretical essay that presents reflections on the possibilities and challenges imposed by the National Common Curricular Base. For this, it proposes a discussion on republic and democracy, locating the school as a training institution necessary for the functioning of society. Finally, we seek to analyze the process of preparing the base, highlighting that although the implementation of a common curriculum is important for the legitimation of Physical Education as a necessary curricular component for the republican school, the final process of the construction of the document occurred in an undemocratic way, challenging its legitimacy.
\end{abstract}

KEYWORDS: Physical education; Republican school; BNCC

\section{Educación Física en BNCC: desafíos de la escuela republicana}

\section{RESUMEN}

El presente estudio consiste en un ensayo teórico que presenta reflexiones sobre las posibilidades y desafíos que impone la Base Curricular Común Nacional. Para ello propone una discusión sobre república y democracia, ubicando a la escuela como una institución de formación necesaria para el funcionamiento de la sociedad. Finalmente, buscamos analizar el proceso de elaboración de la base, resaltando que, si bien la implementación de un currículo común es importante para la legitimación de la Educación Física como componente curricular necesario para la escuela republicana, se dio el proceso final de construcción del documento. de forma antidemocrática, desafiando su legitimidad.

PALABRAS-CLAVE: Educación física; Escuela republicana; BNCC 


\section{INTRODUÇÃO}

O presente ensaio busca problematizar questões relacionadas à república, à democracia e à escola, apresentando um debate sobre as aproximações possíveis entre esses três elementos. A partir disso, tenta responder às seguintes proposições: O que é escola e qual sua função na sociedade hodierna? Como se insere a Educação Física (EF) como componente curricular dentro desse espaço? É importante para a EF possuir um currículo comum a nível nacional?

Iniciaremos com uma discussão sobre as aproximações entre república e democracia a partir de Ribeiro (2008, 2013). Feito isso, refletiremos sobre a escola sob a ótica republicana de González e Fensterseifer $(2009,2010)$, mostrando-a como um projeto institucional elementar para um projeto de fundo democrático e republicano. Por último, analisaremos como a implementação de um currículo mínimo é importante para a consolidação da EF como componente do campo curricular, mas que, para ter legitimidade, o processo de elaboração da BNCC deveria ter respeitado os trâmites democráticos (RIBEIRO, 2013; NEIRA, 2017).

\section{REPÚBLICA, ESCOLA E DEMOCRACIA: aproximações possíveis}

Para Ribeiro (2013, p. 6), “A democracia é o regime do povo comum, em que todos são iguais." Ou seja, é um tipo de organização da sociedade na qual todos os sujeitos possuem os mesmos direitos perante a lei. Segundo o autor, trata-se de um valor, um bem que precisa ser expandido para várias esferas de existência humana. Já república, ainda segundo Ribeiro (2008, p. 72), é um conceito romano, que vem de res publica, que significa coisa pública, e seu ideal “[...] está na dedicação à coisa comum ou coletiva.” Para o autor, ambas podem ser compreendidas “[...] como dois impulsos, pulsões, tendências - enfim, modos de organizar no quadro da política experiências humanas relevantes" (Ibid., p. 5).

Embora sejam regimes distintos, de acordo com Ribeiro (2013, p. 29), ao se considerar a conjuntura societal moderna, o ideal é pensar a organização política "[...] a partir de duas lógicas distintas e mesmo opostas, mas ambas necessárias, a da democracia e a da república.” Isso porque, para o filósofo brasileiro, uma complementa a outra, sendo problemático pensar uma república sem democracia e vice-versa.

Sendo assim, explicita o autor que

[...] o indispensável na política atual passa por duas exigências, que são a da democracia e a da república. A república é o que nos faz respeitar o bem comum. A democracia é o que nos faz construir uma sociedade da qual esperamos nosso bem. 
Na democracia, desejamos ter e ser mais. Com a república, aprendemos a conter nossos desejos. Há uma tensão forte entre os dois princípios, mas um não vive sem o outro (RIBEIRO, 2013, p. 5).

Nessa mesma perspectiva, o autor aponta que democracia e república são duas vertentes que não se conciliam com facilidade, requerendo dos cidadãos um esforço coletivo no intuito de conciliá-las. Para Ribeiro (2008, p. 36), esse é um dos grandes desafios da sociedade moderna, tendo em vista que "Não há política digna desse nome, hoje, que não seja republicana e democrática."

Ribeiro (2008, 2013) também destaca que em sociedades republicanas (de regime democrático) é necessária a existência de algumas instituições que são criadas com o intuito de servir ao Estado. Na visão de González e Fensterseifer (2009, p. 17), “[...] uma república demanda instituições fortes, elas possuem um caráter democratizador, uma vez que protegem o mundo das tiranias." Para Carvalho (1996), é no bojo das instituições democráticas que nasce a instituição escolar, a qual, argumenta o autor, é a principal responsável por conservar e transmitir às novas gerações conhecimentos e saberes pertencentes ao patrimônio histórico e cultural da humanidade.

Assim, para Riberio (2008), a escola figura entre as mais destacadas instituições republicanas, recebendo como designação primária a socialização humana, via processo de ensino/aprendizagem. Ou seja, na compreensão do autor, a escola é um espaço onde devem ser possibilitadas situações que despertem os sujeitos para a ação cidadã, a qual, completar-se-á “[...] na escola da vida, que é a da relação com o outro - ou seja, a participação na vida social" (SOARES, 2008, p. 34).

Para Fensterseifer (2013), a escola é um projeto democrático consolidado, mas que, hodiernamente, vem tendo sua importância contestada, o que põe em pauta seu sentido/significado, bem como sua legitimidade. Na perspectiva teórica desse autor, é importante compreender a escola a partir do seu caráter republicano, isto é, como um espaço comprometido "com a necessidade que as novas gerações têm de conhecimentos capazes de potencializá-los para enfrentar os desafios do mundo contemporâneo" (GONZÁLEZ; FENSTERSEIFER, 2009, p. 12).

Segundo Arendt (2011), a instituição escola, localizada em uma sociedade republicana, tem a incumbência de possibilitar à criança sua inserção no mundo, fazendo uma espécie de ponte entre a vida no sentido privado e a vida de caráter público. Para essa autora, embora a escola não seja o único espaço formativo de que dispõem os sujeitos, ela ainda é a instituição que melhor garante que seja legado à posteridade o conhecimento necessário à formação cidadã.

Nesse contexto, Almeida (2016, p. 22) define a escola republicana como "[...] uma aposta em uma formação humana mais ampla que teria como função estabelecer uma relação que 
incorpore, além do ler, escrever, a capacidade de falar, pensar e julgar.” Ela é, na visão do autor, a responsável por dar subsídios para a atuação dos sujeitos no espaço público.

Conforme Garcia (2009, p. 199), as escolas, quando alinhadas aos

[...] princípios republicanos e democráticos da igualdade, da liberdade, da pluralidade, devem oferecer às crianças e jovens as condições materiais e espirituais para que possam, quando adultas, assumir e desenvolver seus pendores e talentos particulares, bem como suas responsabilidades e iniciativas cidadãs.

Considerando esse debate, Forquin (1993, p. 133) defende que, em uma sociedade republicana e democrática, a transmissão de “[...] um mínimo de saberes comuns, de referências e de valores comuns pode parecer politicamente indispensável.” Isto é, a instituição escolar tem por dever trabalhar os conteúdos consolidados e constituídos como elementares para a inserção na sociedade.

Ao refletir sobre a finalidade da escola, Almeida (2016), dialogando com González e Fensterseifer (2010), aponta que essa deve apresentar aos alunos o patrimônio cultural produzido pelos humanos. No entanto, destaca o autor que não se trata de todo o acervo cultural que deve ser tematizado pela escola, mas sim os “[...] elementos de um passado que entendemos necessários para que estes possam se sentir em casa no mundo e sejam capazes de interpretá-los e reinventá-los no tempo presente, pois sempre há uma escolha” (ALMEIDA, 2016, p. 65).

Nesse sentido, cabe ressaltar que a escola deve se articular ao projeto de sociedade da qual faz parte, assegurando que os estudantes aprendam valores condizentes com uma sociedade democrática de direito. Para Boscatto, Impolcetto e Darido (2016), tais pressupostos referem-se à necessidade de adquirir conhecimentos e saberes que habilitem os sujeitos ao exercício da cidadania e à atuação na esfera democrática. Para isso, esta instituição deve ancorar-se em pressupostos constitucionais que lhe deem prerrogativa para desempenhar tal função.

Mediante esse panorama, Martinelli et al. (2016) salientam que, em uma sociedade democrática, os sujeitos devem ser cidadãos, de forma que a educação deve prover meios para que eles aprendam os mecanismos necessários para exercer a cidadania. Em outras palavras, a escola desempenha o papel de trabalhar com conhecimentos que desenvolvam competências nos estudantes, capacitando-os para o exercício da cidadania e a participação na esfera política. Para tanto, os autores alertam que a sociedade deve apostar numa escola republicana, pois, corroborando com Almeida (2016, p. 24), é nela que se encontra a possibilidade de que os propósitos educacionais sejam revistos em toda a sua complexidade, pois é incumbência sua "oferecer às novas gerações uma instrução pública comum e igualitária que forneça as competências necessárias para 
ganharem visibilidade (quando adultas) e intervirem no mundo comum e de iguais (espaço público)".

Feitas essas considerações a respeito dessa instituição moderna e seu caráter formador do "espírito republicano" (GONZÁLEZ; FENSTERSEIFER, 2009, p. 19), é imperativo fazer a seguinte indagação: Como se insere nesse contexto a EF? Qual deve ser o projeto para esse componente curricular? A EF pode contribuir para esse projeto democrático de sociedade e escola?

\section{A EDUCAÇÃO FÍSICA NA ESCOLA REPUBLICANA}

A EF é um componente curricular com o compromisso de trabalhar conhecimentos que possibilitem formar sujeitos capazes de lidar com os desafios da contemporaneidade. Para González e Fensterseifer (2009, p. 12), sua finalidade é ser “[...] responsável por um conhecimento específico (inclusive conceitual), subordinado a funções sociais de uma escola republicana (GONZÁLEZ; FENSTERSEIFER, 2009, p. 12)". Desse modo, como se insere a EF numa perspectiva de escola republicana?

Primeiro, é preciso estar atento ao que preconiza Fensterseifer, Almeida e Silva (2019) no tocante às características fundantes da EF como campo curricular. Para esses autores, a EF não tem o compromisso exclusivista de formar cidadãos. Não obstante a isso, ela elenca conhecimentos e competências que empoderam os estudantes para "uma inserção reflexiva com o mundo que lhes couber viver" (FESTENSEIFER; ALMEIDA; SILVA, 2019, p. 4). Os autores também chamam atenção para o fato de que a cidadania se dá no âmbito do agir, sendo então necessário um maior alinhamento entre o que se aprende (conceitualmente) e a ação cotidiana.

Ainda nesse sentido, Fensterseifer, Almeida e Silva (2019) apontam a necessidade de a EF, como um componente curricular, responder pelo caráter republicano da instituição à qual está vinculado. Para ele, a EF numa perspectiva republicana trata das diversas manifestações da cultura corporal de movimento, “[...] procurando, ao tematizá-las, desnaturalizá-las, evidenciando a pluralidade de sentidos/significados que os sujeitos podem dar a elas" (FENSTERSEIFER; ALMEIDA; SILVA, 2019, p. 8). Importante ressaltar que o caráter republicano e democrático da instituição escola é o que garante a pluralidade de sentidos/significados no processo educativo, sendo necessário a sociedade valorizar e zelar por isso.

Para Almeida (2016), é incoerente pensar a EF numa escola republicana sem dimensionar o papel do professor dentro dela. Para esse autor, o professor é um cidadão que compactua desse projeto societário e tem a incumbência de “[...] oportunizar às novas gerações a apropriação das diferentes manifestações da cultura corporal de movimento como construções históricas e culturais 
[...]" (Ibid., p. 28). O autor também enfatiza que essa apropriação precisa dar conta de auxiliar os alunos a compreenderem de maneira crítica e analítica os temas-conteúdos, potencializando os meios para o exercício da cidadania.

A partir dessas colocações, é importante indagar sobre os mecanismos democráticos necessários para assegurar a EF na escola republicana. Há meios legais e legítimos que impõem à escola a oferta desse componente curricular? Os documentos normativos podem contribuir para a legitimação da EF como campo curricular? É principalmente acerca dessas questões que a discussão a seguir se ocupa.

\section{A BNCC NA ESCOLA REPUBLICANA: limites e possibilidades de uma base para a educação contemporânea}

De acordo com Arendt (2004, p. 280), é premissa do Estado (republicano e democrático) “[...] prescrever exigências mínimas para a futura cidadania e, além disso, promover e apoiar o ensino de temas e profissões que são consideradas desejáveis e necessárias para a nação como um todo". Portanto, ele deve possuir políticas com orientações acerca da formação do cidadão que ocupará a sociedade. É a partir dessa premissa que são criados os documentos regulatórios, que surgem no intuito de garantir essa prerrogativa estatal.

Nessa perspectiva, Boscatto, Impolcetto e Darido (2016) afirmam que as sociedades republicanas são permeadas por processos formais (leis, decretos, diretrizes, entre outros) que têm a intenção de garantir o status democrático das instituições que a compõem. A escola como uma instituição republicana conserva essa característica de modo muito claro, haja vista os diversos documentos legais que a regem.

Fensterseifer e González (2013) chamam atenção para o fato de que a escola republicana não é um projeto acabado. Por esse motivo, com as mudanças frequentes na sociedade, novas formas de organização devem ser pensadas para que a escola continue tendo sua importância comprovada para os sujeitos que dela necessitam. Para os autores, é nesse contexto que são elaboradas normas e diretrizes que asseguram as condições necessárias para que a escola consiga desempenhar as tarefas que lhes são atribuídas. No Brasil, a mais recente direção tomada nesse sentido foi a elaboração da Base Nacional Comum Curricular (BNCC).

A BNCC trata-se de um documento de "[...] caráter normativo que define o conjunto orgânico e progressivo de aprendizagens essenciais que todos os alunos devem desenvolverão longo das etapas e modalidades da Educação Básica [...]” (BRASIL, 2017, p. 7). É orientada por princípios éticos, políticos e estéticos, visando à formação plena do estudante. A base foi elaborada 
visando à superação das fragmentadas políticas educacionais, construindo um documento coeso que contribuísse para balizar a educação de qualidade.

A BNCC é um tipo de documento normativo que deriva da incumbência estatal apontada por Arendt (2004). Por isso, tem por orientação contribuir para a qualidade da educação nacional, haja vista o caráter republicano da construção de uma base. Em outros termos, o sentido de existência da BNCC é garantir um currículo mínimo para o sistema educacional brasileiro. Ou seja, é a definição pelo Estado dos conhecimentos que todo estudante que passar pela escola deve aprender.

Importante destacar que a BNCC é garantida por pelo menos quatro documentos legais, a saber: a Constituição Federal (1998), a Lei de Diretrizes e Bases da Educação (1996), além das Diretrizes Curriculares Nacionais (2013) e do Plano Nacional de Educação (2014-2024). Todos esses documentos normativos eram enfáticos quanto à necessidade de o país possuir um “currículo mínimo" para que houvesse uma formação básica comum a todos os cidadãos brasileiros alfabetizados.

Boscatto, Impolcetto e Darido (2016) apontam que todas essas orientações por um currículo mínimo têm em comum a compreensão de que a educação apresenta problemas que dificultam a prática pedagógica do professor, sobretudo em relação ao ensinar/aprender. Assim, para as autoras, o país possuindo uma base curricular poderá contribuir para a facilitação do processo pedagógico, além de dar condições similares a todos os estudantes de se apropriarem dos conhecimentos e saberes oriundos da cultura universal, que serão sistematizados nos currículos.

Um dos pontos nevrálgicos da BNCC é seu reconhecimento de que a sociedade vem sofrendo mudanças e que a educação precisa acompanhar esse processo sob o risco de perder sua condição de necessária para a república. Nesse sentido, esse novo cenário requer dos sujeitos "reconhecer-se em seu contexto histórico e cultural, comunicar-se, ser criativo, analítico-crítico, participativo, aberto ao novo, colaborativo, resiliente, produtivo e responsável requer muito mais do que o acúmulo de informações" (BRASIL, 2017, p. 14). Essa colocação corrobora aquilo que destacam Fensterseifer, González e Silva (2009) a respeito da necessidade de a escola estar preocupada com os sujeitos do hoje, com aqueles que participarão da vida democrática e encontram na escola a possibilidade de desenvolver as potencialidades para esse agir.

Além disso, a BNCC defende uma formação integral dos sujeitos, "rompendo com visões reducionistas que privilegiam ou a dimensão intelectual (cognitiva) ou a dimensão afetiva (BRASIL, 2017). Ou seja, devem ser considerados os sujeitos em todas as suas dimensões, garantindo o respeito às diferenças e à pluralidade, características tão caras às sociedades democráticas. Características das quais "só instituições com esse caráter pode preservar e que não 
são necessariamente compatíveis com os marcos de outros modos humanos de organizar a vida em sociedade" (FENSTERSEIFER; GONZÁLEZ; SILVA, 2019).

Para Chan Vianna (2016, p. 6), a BNCC representa "[...] claramente uma luta política e histórica da Educação Física, qual seja, combater um currículo informal que apresenta apenas um conteúdo ou conjunto semelhante de conteúdos (geralmente esportivos)." No entanto, o autor destaca que é preciso os sistemas de ensino estarem atentos para que não organizem seus currículos de modo engessado.

Chan Vianna (2016) ainda argumenta que a EF não pode querer se assemelhar às demais disciplinas constituindo um corpo de disciplinas muito fechadas. Para esse autor, uma possível saída para esse campo de intervenção escolar seria tornar o jogo como central para o ensino/aprendizagem, partindo dele para a tematização das demais práticas corporais. Isso porque, na visão do autor, não possuímos “[...] uma gramática elementar e com os conhecimentos necessários cronologicamente sistematizados para o aluno explorar com autonomia todas as possibilidades de práticas típicas da Educação Física” (Ibid., p. 7).

Notamos, a partir de todas essas caraterísticas apontadas acerca da BNCC, que a base nacional, além de um documento que encontra prerrogativa legal, também se apresentava como uma possível solução para alguns problemas presentes na área (BOSCATTO; IMPOLCETTO; DARIDO, 2016; SILVA; MARTINS; SILVA, 2017; NEIRA; SOUZA JÚNIOR, 2016), principalmente a elaboração e consolidação de um currículo nacional. Entretanto, a construção, a implementação e, sobretudo, a efetivação de políticas para a Educação em uma sociedade republicana e democrática devem garantir os trâmites legais, assegurando assim um processo democrático, sob o risco de se configurarem processos autoritários e impositivos.

Então, vários sujeitos acompanharam o processo de elaboração da BNCC, contribuindo para as diferentes visões sobre o documento. Para Tavares, Garcia e Rodrigues (2019), até o ano de 2018, o campo se dividia em três tendências em relação ao posicionamento acerca da construção/implementação da BNCC: a) aqueles que eram otimistas e favoráveis; b) aqueles que eram favoráveis à base, mas ligavam o documento a interesses político-econômicos de empresários da Educação; e c) aqueles contrários à necessidade e finalidade de uma base comum para o país.

Nesse sentido, serão apresentadas, a seguir, duas principais reflexões: a primeira centra nos pontos positivos sobre a implementação de uma base comum; a segunda problematiza como o modo pelo qual a terceira versão do documento foi construída afetou sua legitimidade. A partir disso, são lançadas as seguintes proposições: 1) O modo como foi produzida a BNCC garantiu as condições necessárias de participação democrática dos sujeitos? 2) Em que medida a BNCC incorporou os ideais de uma sociedade republicana que aspira à democracia? 3) Qual o lugar que os 
professores de EF tiveram na construção da base, assegurando a participação? 4) Quais contribuições reais a BNCC pode proporcionar à área após sua efetivação?

Responder essas questões é necessário para localizar o lugar que se coloca a BNCC na sociedade, salientando que república e democracia não são apenas conceitos, mas se constituem como projetos históricos e sociais com valores a serem resguardados.

\section{BNCC E EDUCAÇÃO FÍSICA: da possibilidade de organização curricular da área ao desfecho pouco democrático}

Para Neira (2017), o processo de elaboração da BNCC se divide em duas etapas notadamente opostas. A primeira, denominada pelo autor como BNCC-II, engloba as fases preliminares da construção da base até a finalização da segunda versão do documento; e a segunda fase, denominada BNCC-III, a qual se consolidou como a versão final homologada.

Na visão de Neira e Souza Júnior (2016), a BNCC, em sua segunda versão, guardava características democráticas, e sua implementação possibilitaria a construção de uma sociedade mais justa e digna. Para esses autores, o maior traço que evidenciava isso se deu no processo de construção do documento no qual a participação de diversos setores da sociedade foi garantida via reuniões e seminários, além do recurso de contribuição por plataforma on-line que havia sido disponibilizado pelo Ministério da Educação (MEC).

Essa versão, segundo Neira (2017, p. 1), “[...] foi produzida por uma equipe de 135 profissionais, entre professores da Educação Básica e do Ensino Superior, representantes de todas as unidades da federação.” O autor destaca que foram mais de 12 milhões de contribuições para o documento que envolviam leitura apurada de profissionais, especialistas, além dos debates que ocorreram em todo o Brasil.

$\mathrm{Na}$ visão de muitos autores, a BNCC-II possibilitaria dar legitimidade ao currículo escolar da EF, uma vez que, além de potencializar a formação de sujeitos críticos, colaboraria para democratizar o conhecimento da área, já que construiria um corpo de conteúdos "obrigatórios" a serem tematizados em todas as escolas do país (NEIRA; SOUZA JÚNIOR, 2016; BOSCCATO; IMPOLCETTO; DARIDO, 2016; SILVA; MARTINS; SILVA, 2017).

Isso vai de encontro com a defesa de alguns autores de que a $\mathrm{EF}$, como componente do currículo obrigatório da escola republicana, historicamente apresenta um problema de difícil resolução, a saber: a consolidação de um currículo comum a ser desenvolvido em todas as escolas brasileiras. Diferentemente do que ocorre com outros componentes curriculares, que apresentam um conjunto de conhecimentos consolidados, com a $\mathrm{EF}$, apesar de todo o debate produzido nas últimas décadas, parece não haver essa consolidação. Esse problema, no entendimento de autores de renome 
na área, tem caracterizado uma certa "bagunça curricular" que persiste em não ser resolvida (KUNZ, 1994; OLIVEIRA, 2002; NASCIMENTO, 2005; IMPOLCETTO et al., 2007), sendo a BNCC uma solução viável para tal impasse.

Como se vê, a literatura a respeito dessa questão é um tanto vasta. Nesse sentido, Kunz (1994) chama atenção para o fato de que um professor de EF pode optar por trabalhar um conteúdo no primeiro ano do ensino fundamental e repeti-lo no segundo ano do ensino médio sem nenhuma alteração, sem, com isso, causar algum estranhamento à escola. Evento que, na ótica do autor, dificilmente ocorreria com qualquer outra disciplina dentro do currículo, independente da etapa escolar. Para Kunz (1994, p. 150), “[...] a organização de um 'programa mínimo’ para a EF deverá, pelo menos, conseguir pôr fim a nossa 'bagunça interna' como disciplina/atividade escolar [...]”. Ou seja, o autor também vê com bons olhos a construção de uma base comum.

Já segundo Paes (2002), a não diversificação dos conteúdos, bem como a falta de um aumento de nível de exigências no decorrer das etapas escolares, é um dos grandes causadores de desmotivação dos alunos. Além disso, para esse autor, com o passar dos anos, sobretudo na segunda parte do ensino fundamental, essa repetição de conteúdos é uma das causas da alta evasão das aulas de EF. O mesmo fato foi constatado por Darido (2014) ao comprovar, em seus estudos, que os estudantes chegam no ensino médio com o grau de motivação para as aulas baixo devido à monotonia das aulas e à repetição dos conteúdos trabalhados.

Desse modo, Impolcetto e Darido (2011) chamam atenção para outro problema que a inexistência de "elementos balizadores" causa. Para as autoras, essa condição alertada transforma o currículo da EF numa pequena seleção dos esportes preferidos do professor regente, o qual utiliza como base para as aulas sua experiência pessoal com determinadas práticas. É um espontaneísmo pedagógico que só prejudica a legitimação da área no campo educativo.

Diante de tal cenário, percebe-se que a produção científica da área já vinha evidenciando a necessidade de uma base comum para EF. A partir de então, criou-se uma grande expectativa por parte desses autores para a possibilidade de reverter uma situação há muito questionada e até agora não resolvida. Ou seja, havia a crença de que a BNCC seria uma possibilidade concreta para resolver a "bagunça interna" da EF, dando mais legitimidade a esse componente curricular.

Apesar do clima favorável à concretização da base, muitos autores ressaltam que alguns eventos comprometeram todo o processo, causando uma verdadeira reviravolta no entendimento acerca da legitimidade da base para a área (NEIRA, 2017; GONZÁLEZ, 2016; CHAN VIANNA, 2106; MARTINELI et al.; RODRIGUES, 2016). A principal crítica endereçada à BNCC foi o ambiente pouco democrático que estava se formando no país naquele momento de elaboração da terceira versão. 
É considerando esse contexto político que González (2016) já chamava atenção sobre os problemas de se avançar na construção da terceira versão da BNCC em função do "clima político" que estava vivendo o país naquele momento. Vale lembrar, na esteira de Neira (2017), que, durante a elaboração da BNCC-III, o país vivia o processo de impeachment de Dilma Rousseff, o que tornava o ambiente pouco favorável à continuidade do debate sobre a base, uma vez que as pautas giravam em torno de outras questões, deixando as discussões sobre o documento secundarizadas.

Para Neira (2017, p. 1), naquela conjuntura, a sociedade brasileira assistia “[...] à retirada de seus direitos e o franco caminhar para um regime antidemocrático estimulado por setores conservadores e empresariais, bem representados nas políticas educacionais em curso.” O que impedia, na visão do autor, que a BNCC fosse levada adiante. Para González (2016), não garantir a participação de toda a comunidade na elaboração da terceira versão da base seria um erro grave e um ato que poderia causar “[...] uma perda de legitimidade irrecuperável para o documento curricular" (Ibid., p. 1).

González (2016) também destacou a necessidade de que o processo democrático fosse respeitado durante a construção da BNCC, pois, na visão do autor, sem essa condição a base não teria "futuro," já que seria reduzida a um documento normativo de caráter técnico e burocrático que não respeitou aos tramites necessários. Com isso, a base nacional perderia sua característica fundamental de “[...] 'acordo' nacional sobre os 'direitos de aprendizagem e desenvolvimento' de crianças e adolescentes. Acordo no qual necessitam participar 'todos' os setores que entendam que tem algo a dizer sobre o tema” (Ibid., p. 1).

Refletindo sobre a elaboração do documento, Chan Vianna (2016, p. 17-18) argumenta que a missão de construir a BNCC deveria ser cuidadosa, observando princípios democráticos para não correr o risco de "[...] ser repelida ou ignorada pela comunidade e, mais sério, não desarticular as bases que tornam a disciplina viva na escola, mesmo que de forma precária em algum sentido." Desse modo, em um dos pareceres sobre a terceira versão da BNCC, o autor se posiciona favorável à ampliação do debate acerca do documento, já que em seu entendimento “[...] ainda é necessário muito avanço e consenso para que a BNCC seja realmente o que se pretende e não mais um documento desmobilizador das iniciativas positivas existentes em diversas escolas no Brasil” (Ibid., p. 20).

Nesse sentido, Neira (2017) enfatiza que as mudanças feitas na terceira versão modificaram substancialmente o conteúdo da BNCC, causando-lhe danos irreparáveis. Segundo Neira (2017, p. 5), a terceira versão da base nacional apresenta uma grande fragilidade que promove um verdadeiro “[...] esvaziamento do potencial crítico e democratizante para dar lugar a uma formação instrumental alinhada aos ditames do mercado.” Com essa constatação, torna-se necessário refletir o 
quanto de democrático foi o processo de construção da versão final do documento. A análise desse momento dificulta a defesa da BNCC-III como uma representação do desejo (republicano) da sociedade com relação aos caminhos que deve tomar a educação nacional.

Em relação às influências que giram em torno da BNCC, Rodrigues (2016, p. 34) destacava que pareciam existir “[...] diferentes interesses públicos e privados, políticos e econômicos, para além dos interesses ligados à necessária construção de uma base nacional de saberes escolares e a melhoria da qualidade da educação brasileira.” Nessa perspectiva de compreensão, Martinelli et al. (2016) apontaram os organismos multilaterais como principais defensores e elaboradores da base nacional, a qual está alinhada com compreensões pedagógicas que colocam a educação como formadora de mão de obra para o mercado de trabalho, ou seja, como uma instituição de formação exclusiva de competências laborais.

Em relação ao lugar dos professores (de EF) na elaboração da base, constatamos que, além de não terem participado efetivamente do processo de construção da BNCC-III, de acordo com Rufino e Souza Neto (2016), as políticas que envolvem a base nacional ainda falham ao não colocar o trabalho docente como elemento central no processo educativo, compreendendo-os, muitas vezes, apenas como aplicadores de teorias. Segundo os autores, esse fato promove um “[...] desacordo com os processos que buscam legitimar a profissionalização do ensino" (Ibid., p. 45).

Mediante esse quadro, Martinelli et al. (2016), ao analisarem a BNCC, destacam que o documento possui uma orientação quase que exclusivamente voltada para o aluno, colocando a função pedagógica do professor de forma secundarizada. Para os autores, isso dificulta o processo de ensino/aprendizagem, descaracterizando a função docente em um processo no qual o aluno torna-se o centro do processo, sendo então o único responsável por seu aprendizado.

Arroyo (2016) diz ser incapaz de localizar na BNCC a voz dos professores (de EF), que são os principais envolvidos no processo educativo. Para o autor, isso causa a impressão de que os professores são meros executores de políticas educacionais, não possuindo capacidade de contribuir efetivamente para a elaboração dos documentos que impactaram diretamente a sua prática docente.

Nesse sentido, é importante destacar que não se pode cair na ingenuidade de acreditar que o simples fato de existir uma base resolveria a "bagunça interna" da EF (KUNZ, 1994), muito menos omitir o fato de que o processo de elaboração da BNCC-III foi aligeirado, confuso e pouco democrático, no qual prevaleceram questões alheias ao interesse pedagógico ligadas, sobretudo, aos interesses do mercado de trabalho (MARTINELLI et al., 2016; MOREIRA et al., 2016; RODRIGUES, 2016).

Também é preciso destacar, na esteira de Souza (2017), que a BNCC-III, na versão amparada pela Lei n. ${ }^{\circ}$ 13.417/2017, a qual ratificou a reforma do ensino médio, manteve a EF na 
marginalidade. Para Marciel (2019), a EF deixa de ser um conteúdo obrigatório no ensino médio para então ocupar, juntamente com Sociologia, Filosofia e Artes, o posto de "estudos e práticas". Para o autor, o uso dessas nomenclaturas “[...] intencionalmente mais vagas e imprecisas do que os termos 'ensino e oferta', utilizados para os componentes curriculares obrigatórios," evidenciam o lugar que a EF ocupa nesse novo documento (Ibid., p. 4).

Assim, em vez de a base poder possibilitar a resolução de um antigo impasse, qual seja, organizar a "bagunça interna", possibilitando assim a consolidação de um currículo comum para a área em função do processo pouco democrático da elaboração da BNCC-III, o que se "conquistou" para a sociedade foi um documento dúbio e com pouca legitimidade (NEIRA, 2017). Por consequência, a EF parece ter sidopouco valorizada na BNCC-III, principalmente no ensino médio. Esse fato evidencia que, embora as bases nacionais sejam parte necessária de um projeto de sociedade republicana e democrática, é imperativo que, no processo de elaboração de tais normativas, o respeito ao processo democrático seja resguardado. Somente assim será garantida a participação dos cidadãos na tomada de decisões, visando sempre à garantia do bem comum (RIBEIRO, 2008, 2013).

\section{CONSIDERAÇÕES FINAIS}

Tomando o processo de elaboração da BNCC-III como exemplo de um caso isolado, somando-o a uma série de eventos que tem ocorrido com uma frequência assustadora em nosso país, chegamos à conclusão de que a defesa de um projeto histórico com fundo democrático e republicano é uma tarefa urgente e necessária da qual todos temos de nos encarregar. O Brasil com sua recente democracia precisa reforçar suas instituições de modo a garantir sua sobrevivência (RIBEIRO, 2013). E precisamos colocar a escola como uma instituição fundamental para materialização desse projeto.

Corroboramos assim a afirmativa de Libâneo (1992) de que, dentre os principais objetivos da escola, encontra-se a necessidade de se contribuir para a formação de sujeitos capazes de dar continuidade ao projeto democrático, tendo por dever colocar a EF como componente desse processo. Nesse sentido, é necessário pontuar que a sua organização como componente curricular precisa potencializar elementos formativos necessários para que os estudantes sejam capazes de atuar na nossa sociedade de forma democrática.

Com base nessas considerações, procuramos, com este ensaio, estabelecer um diálogo sobre a escola e suas prerrogativas como instituição republicana. Além disso, evidenciamos a EF como um componente curricular comprometido com a manutenção e efetivação do projeto republicano de escola. Finalizamos, por fim, apontando que a BNCC (até sua segunda versão) apresentou-se como 
uma possibilidade real para organização dos currículos da EF, tendo como horizonte potencializar os meios para exercício da cidadania e formação do espírito republicano. No entanto, talvez em função da pouca experiência democrática do país (RIBEIRO, 2008, 2013), o que se viu foi um ambiente instável e pouco democrático no qual seria impossível tomar qualquer decisão, sobretudo com relação ao destino da Educação de toda uma nação.

Portanto, a sensação que fica é que o país perdeu uma grande oportunidade, mostrando-nos que ainda temos um grande desafio pela frente - no qual a escola e a EF devem contribuir efetivamente -, qual seja, construir bases mais sólidas para a garantia e a consolidação de um projeto de sociedade de caráter republicano e democrático.

\section{REFERÊNCIAS}

ALMEIDA, Luciano de. Linguagem e experiência: pensando a Educação Física na escola republicana. 2016. 96 f. Tese (Doutorado nas Ciências) - Universidade Regional do Noroeste do Estado do Rio Grande do Sul, Ijuí, 2016.

ARENDT, Hannah. Responsabilidade e julgamento. São Paulo: Companhia das Letras, 2004.

ARENDT, Hannah. A crise na educação. In: Entre o passado e o futuro. 7. ed. São Paulo: Perspectiva, 2011.

ARROYO, Miguel González. Corpos resistentes produtores de culturas corporais. Haverá lugar na Base Nacional Comum? Motrivivência, Florianópolis, v. 8, n. 48, p. 15-31, 2016. Disponível em: https://periodicos.uff.br/revistamovimento/article/view/32889/22298. Acesso em: 27 set. 2020.

BOSCATTO, Juliano Daniel; IMPOLCETTO, Fernanda Moretto; DARIDO, Suraya Cristina. A Base Nacional Comum Curricular: uma proposição necessária para a educação física? Motrivivência, Florianópolis, v. 28, n. 48, set. 2016. Disponível em:

https://periodicos.ufsc.br/index.php/motrivivencia/article/view/21758042.2016v28n48p96/32565. Acesso em: 26 set. 2020.

BRASIL. Ministério da Educação. Diretrizes Curriculares Nacionais da Educação Básica. Brasília, DF: MEC, 2013.

BRASIL. Constituição Federal. Brasília, DF: DOU, 1988.

BRASIL. Lei de Diretrizes e Bases da Educação. Brasília, DF: DOU, 1996.

BRASIL. Base Nacional Comum Curricular. $3^{\text {a }}$ versão, Brasília, DF: MEC,2017. Disponível em: http://basenacionalcomum.mec.gov.br/. Acesso em: 25 set. 2020.

BRASIL. Parecer sobre a Base Nacional Comum Curricular $3^{\text {a }}$ Versão. Relator: Fernando Jaime González, 2016. Disponível em: http://basenacionalcomum.mec.gov.br/pareceres. Acesso em: 26 set. 2020.

BRASIL. Parecer sobre a versão 3 da BNCC para a Educação Física. Relator: Alexandre Jackson Chan Vianna, 2016. Disponível em: http://basenacionalcomum.mec.gov.br/pareceres. Acesso em: 25 set. 2020.

CARVALHO, José Silva. Algumas reflexões sobre o papel da escola de $2^{\circ}$ grau. Revista Paulista de Educação Física, São Paulo, Suplemento 2, p. 36-39, 1996. 
DARIDO, Suraya Cristina. A Educação Física na escola e o processo de formação dos não praticantes de atividade física. Revista Brasileira de Educação Física e Esporte, São Paulo, v.18, n. 1, p.61-80, jan./mar. 2004.

FENSTERSEIFER, Paulo Evaldo. Linguagem, hermenêutica e atividade epistemológica na Educação Física. Movimento, Porto Alegre, v. 15, n. 4, p. 243-256, 2009.

FENSTERSEIFER, Paulo Evaldo; GONZÁLEZ, Fernando Jaime. Desafios da legitimação da Educação Física na escola republicana. Horizontes - Revista de Educação, Dourados, MS, n. 2, v1, jul./dez. 2013.

FENSTERSEIFER, Paulo Evaldo; GONZÁLEZ, Fernando Jaime; SILVA, Sidinei Pithan da. Educação Física crítica em perspectiva democrática e republicana. Movimento, Porto Alegre, v. 25, e25070, 2019. Disponível em: https://seer.ufrgs.br/Movimento/article/view/95771/54837. Acesso em: 27 set. 2020.

FORQUIN, Jean-Claude. Escola e Cultura: As bases sociais e epistemológicas do conhecimento escolar. Tradução Guacira Lopes Louro. Porto Alegre: Artes Médicas, 1993.

GARCIA, Claudio Boeira. Considerações sobre a república, democracia e educação. Contexto \& Educação, Ijuí, v. 24, n. 82, p. 189-204, jul./dez. 2009.

GONZÁLEZ, Fernando Jaime; FENSTERSEIFER, Paulo Evaldo. Entre o "não mais" e o "ainda não": pensando saídas do não-lugar da educação física escolar II. Cadernos de Formação RBCE, p. 9-24, set. 2009.

GONZÁLEZ, Fernando Jaime; FENSTERSEIFER, Paulo Evaldo. Entre o "não mais" e o "ainda não": pensando saídas do não-lugar da educação física escolar II. Cadernos de Formação RBCE, p. 10-21, mar. 2010 .

IMPOLCETTO, Fernanda Moretto; DI THOMAZZO, Aline; BONFÁ, Ana Cristina; BARROS, André Minuzzo; SÁ, Carolina, Strausser; BROUCO, Gisely, Rodrigues; RODRIGUES, Heitor; TERRA, Janaína; IÓRIO, Laércio Schwantes; VENÂNCIO, Luciana; ROSÁRIO, Luiz Fernando; SOUZA JÚNIOR, Osmar; GASPARI, Telma; BATTISTUZZI, Valéria Marciel; DARIDO, Suraya Cristina. Educação física no ensino fundamental e médio: a sistematização dos conteúdos na perspectiva de docentes universitários. Revista Mackenzie de Educação Física e Esporte, v. 6, p. 89-109, 2007.

IMPOLCETTO, Fernanda Moretto; DARIDO, Suraya Cristina. Possibilidades para a sistematização do voleibol na Educação Física escolar. Revista Brasileira de Ciência e Movimento, v.19, n. 2, p. 90-100, 2011.

KUNZ, Elenor. Transformação didático-pedagógica do esporte. Ijuí: Ed. da Unijuí, 1994.

LIBÂNEO, José Carlos. Didática. São Paulo: Cortez, 1992.

MARCIEL, Caroline. Uma avaliação da Lei n. ${ }^{\circ}$ 13.415/17 a partir da logística e das metas do PNE.

Educação \& Realidade, Porto Alegre, v. 44, n. 3, e84925, 2019. Disponível em:

http://www.scielo.br/pdf/edreal/v44n3/2175-6236-edreal-44-03-e84925.pdf\&gt. Acesso em: 27 set. 2020.

MARTINELlE, Telma Adriana Pacífico et al. A Educação Física na BNCC: concepções e fundamentos políticos e pedagógicos. Motrivivência, Florianópolis, v. 28, n. 48, p. 76-95, set. 2016. Disponível em: https://periodicos.ufsc.br/index.php/motrivivencia/article/view/2175-8042.2016v28n48p76/32564. Acesso em: 27 set. 2020.

MOREIRA, Laine Rocha; OLIVEIRA, Marcos Renan Freitas de; SOARES, Marta Genú; ABREU, Meriane Conceição Paiva; NOGUEIRA, Suziane Chaves. Apreciação da base nacional comum curricular e a 
educação física em foco. Motrivivência, Florianópolis, v. 28, n. 48, p. 61-75, 2016. Disponível em: https://periodicos.ufsc.br/index.php/motrivivencia/article/view/21758042.2016v28n48p61/32563. Acesso em: 26 set. 2020.

NASCIMENTO, Marco César Pereira. Uni-Duni-Tê: professores selecionando conteúdos em uma crise da educação física. 2006. Dissertação (Mestrado em Educação) - Universidade Federal de Juiz de Fora, 2006.

NEIRA, Marcos Garcia. Terceira versão da BNCC: Retrocesso político e pedagógico. In: CONGRESSO BRASILEIRO DE CIÊNCIAS DO ESPORTE, 20., 2017, Natal-RN. Anais [...]. Natal-RN: CBCE, 2017. p. 2974-2978.

NEIRA, Marcos Garcia; SOUZA JÚNIOR, Marcílio. A Educação Física na BNCC: procedimentos, concepções e efeitos. Motrivivência,Florianópolis, v. 28, n. 48, p. 188-206, 2016. Disponível em: https://periodicos.ufsc.br/index.php/motrivivencia/article/view/2175-8042.2016v28n48p188/32570. Acesso em: 27 set. 2020.

OLIVEIRA, André Barbosa. Apresentação. In: GRESPAN, M. R. Educação física no ensino fundamental: primeiro ciclo. Campinas: Papirus, 2002. p. 1-122.

RODRIGUES, Anegleyce Teodoro. Base Nacional Comum para a área de Linguagens e o componente curricular Educação Física. Motrivivência, Florianópolis, v. 28, n. 48, p. 32-41, 2016.

PAES, Roberto Rodrigues. A pedagogia do esporte e os jogos coletivos. In: DE ROSE JÚNIOR, D. Esporte e Atividade Física na Infância e na Adolescência:uma abordagem multidisciplinar. Porto Alegre:

Artmed, 2002. p. 1-200.

RIBEIRO, Renato Janine. A República. 2. ed. São Paulo: Publifolha, 2008.

RIBEIRO, Renato Janine.A Democracia. 3. ed. São Paulo: Publifolha, 2013.

RUFINO, Luiz Gustavo Bonatto; SOUZA NETO, Samuel de. Saberes docentes e formação de professores de Educação Física: análise da Base Nacional Comum Curricular (BNCC) na perspectiva da profissionalização do ensino.Motrivivência, Florianópolis, v. 28, n. 48, p. 42-60, 2016. Disponível em: https://periodicos.ufsc.br/index.php/motrivivencia/article/view/21758042.2016v28n48p42/32562. Acesso em: 26 set. 2020.

SILVA, Antônio Jansen Fernandes da; MARTINS, Raphael Moreira; SILVA, Maria Eleni Henrique da. BNCC: o que dizem os professores. In: CONGRESSO BRASILEIRO DE CIÊNCIAS DO ESPORTE, 20., 2017, Natal-RN. Anais [...]. Natal-RN: CBCE, 2017, p. 1347-1352.

SOUZA, Maristela da Silva; RAMOS, Fabrício Krusche. Educação Física e o mundo do trabalho: um diálogo com a atual Reforma do Ensino Médio. Motrivivência, Florianópolis, v. 29, n. 52, p. 71-86, set. 2017. Disponível em:

https://periodicos.ufsc.br/index.php/motrivivencia/article/view/21758042.2017v29n52p71/35031. Acesso em: 27 set. 2020.

TAVARES, Raquel Nunes; GARCIA, Lênin Tomazett; RODRIGUES, Anegleyce Teodoro. Base Nacional Comum Curricular e Educação Física: análise de tendências e lacunas da produção acadêmica no Brasil. Movimento-Revista de Educação, Niterói, ano 6, n.11, p. 185-207, jul./dez. 2019. Disponível em: https://periodicos.uff.br/revistamovimento/article/view/32889/22298. Acesso em: 27 set. 2020.

\section{NOTAS DE AUTOR}


AGRADECIMENTOS - Não se aplica.

CONTRIBUIÇÃO DE AUTORIA - Não se aplica.

FINANCIAMENTO - Não se aplica.

CONSENTIMENTO DE USO DE IMAGEM - Não se aplica

APROVAÇÃO DE COMITÊ DE ÉTICA EM PESQUISA - Não se aplica.

CONFLITO DE INTERESSES - Não se aplica.

LICENÇA DE USO

Os autores cedem à Motrivivência - ISSN 2175-8042 os direitos exclusivos de primeira publicação, com o trabalho simultaneamente licenciado sob a Licença Creative Commons Attribution Non-Comercial ShareAlike (CC BY-NC SA) 4.0 International. Esta licença permite que terceiros remixem, adaptem e criem a partir do trabalho publicado, desde que para fins não comerciais, atribuindo o devido crédito de autoria e publicação inicial neste periódico desde que adotem a mesma licença, compartilhar igual. Os autores têm autorização para assumir contratos adicionais separadamente, para distribuição não exclusiva da versão do trabalho publicada neste periódico (ex.: publicar em repositório institucional, em site pessoal, publicar uma tradução, ou como capítulo de livro), com reconhecimento de autoria e publicação inicial neste periódico, desde que para fins não comerciais e compartilhar com a mesma licença.

\section{PUBLISHER}

Universidade Federal de Santa Catarina. Programa de Pós-Graduação em Educação Física. LaboMídia - Laboratório e Observatório da Mídia Esportiva. Publicado no Portal de Periódicos UFSC. As ideias expressadas neste artigo são de responsabilidade de seus autores, não representando, necessariamente, a opinião dos editores ou da universidade.

\section{EDITORES}

Mauricio Roberto da Silva, Giovani De Lorenzi Pires, Rogério Santos Pereira.

\section{EDITOR DE SEÇÃO}

Rafael Matiuda Spinelli.

\section{REVISÃO DO MANUSCRITO E METADADOS}

João Caetano Prates Rocha; Keli Barreto.

\section{HISTÓRICO}

Recebido em: 21 de julho de 2020.

Aprovado em: 28 de janeiro de 2021. 